
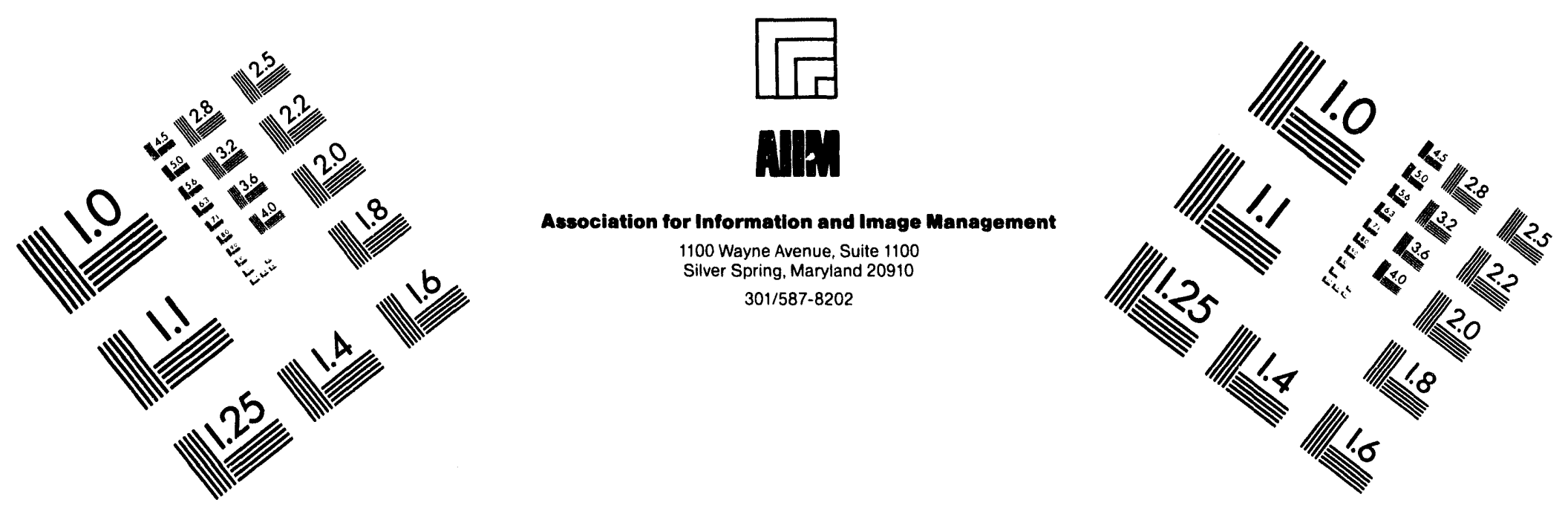

\title{
Centimeter
}

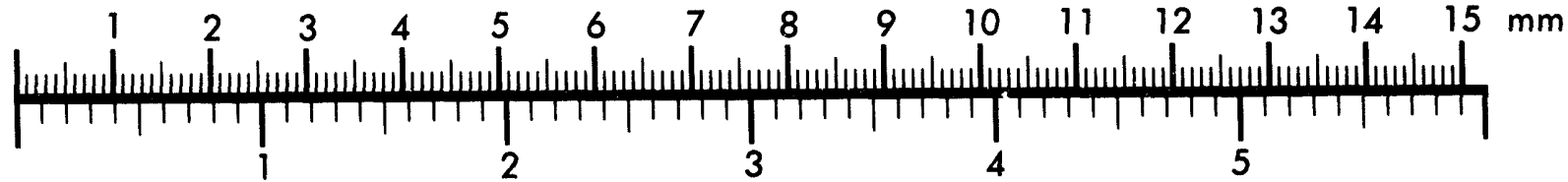
Inches
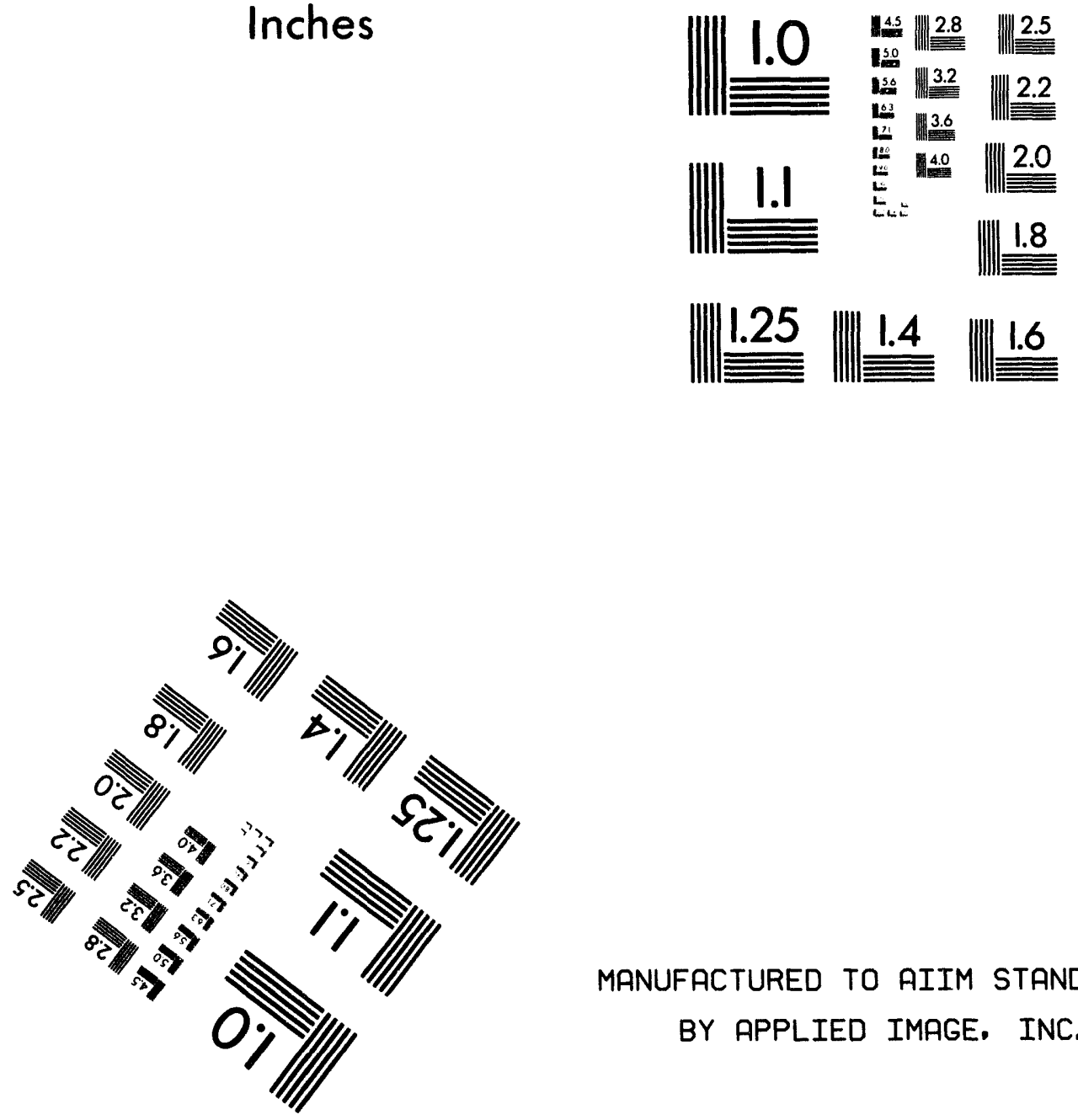

MANUFACTURED TO AIIM STANDARDS

BY APPLIED IMAGE. INC.

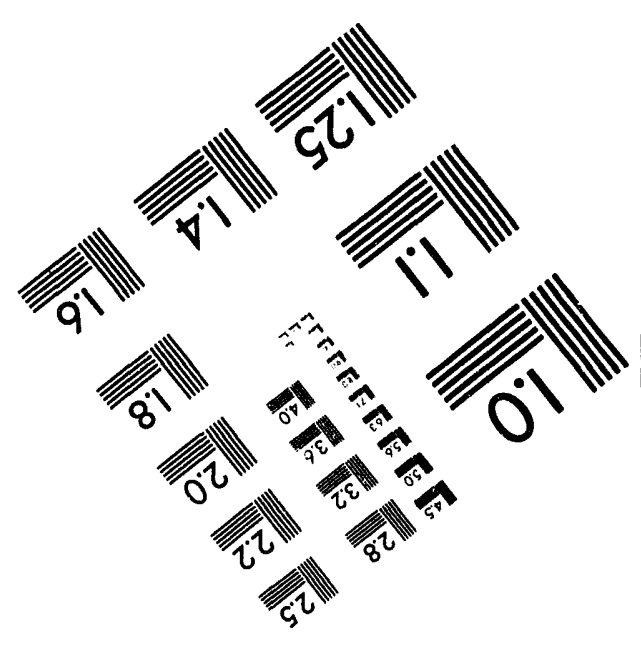



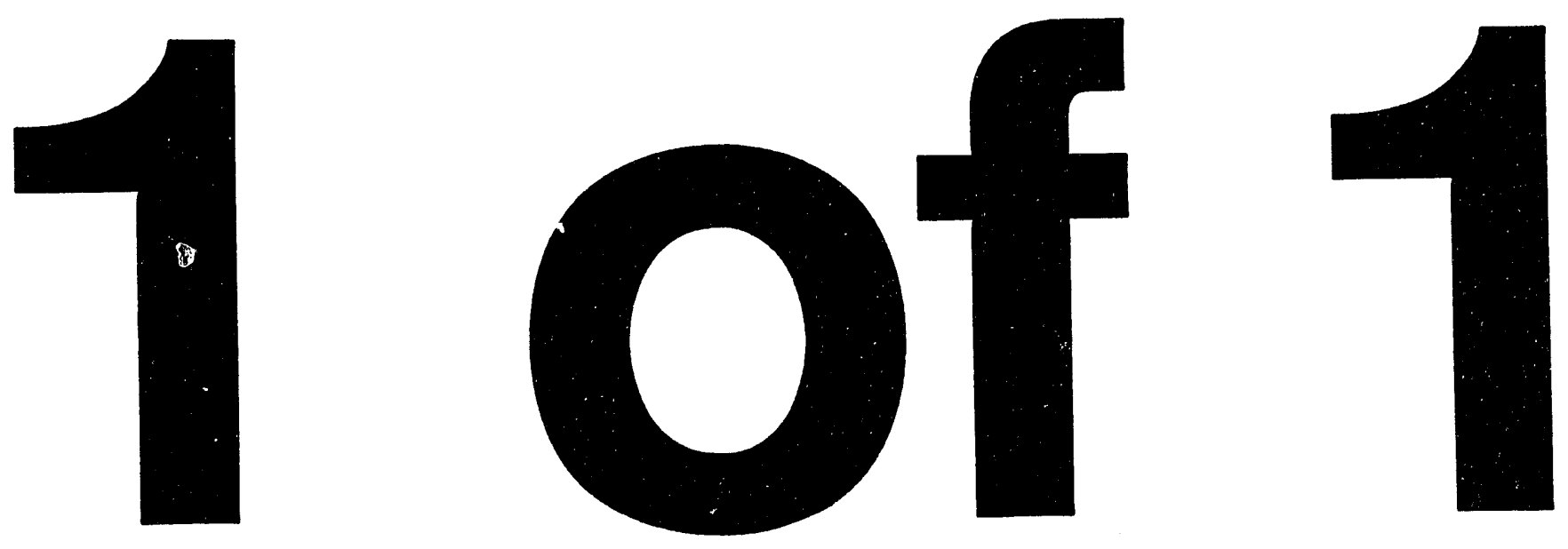

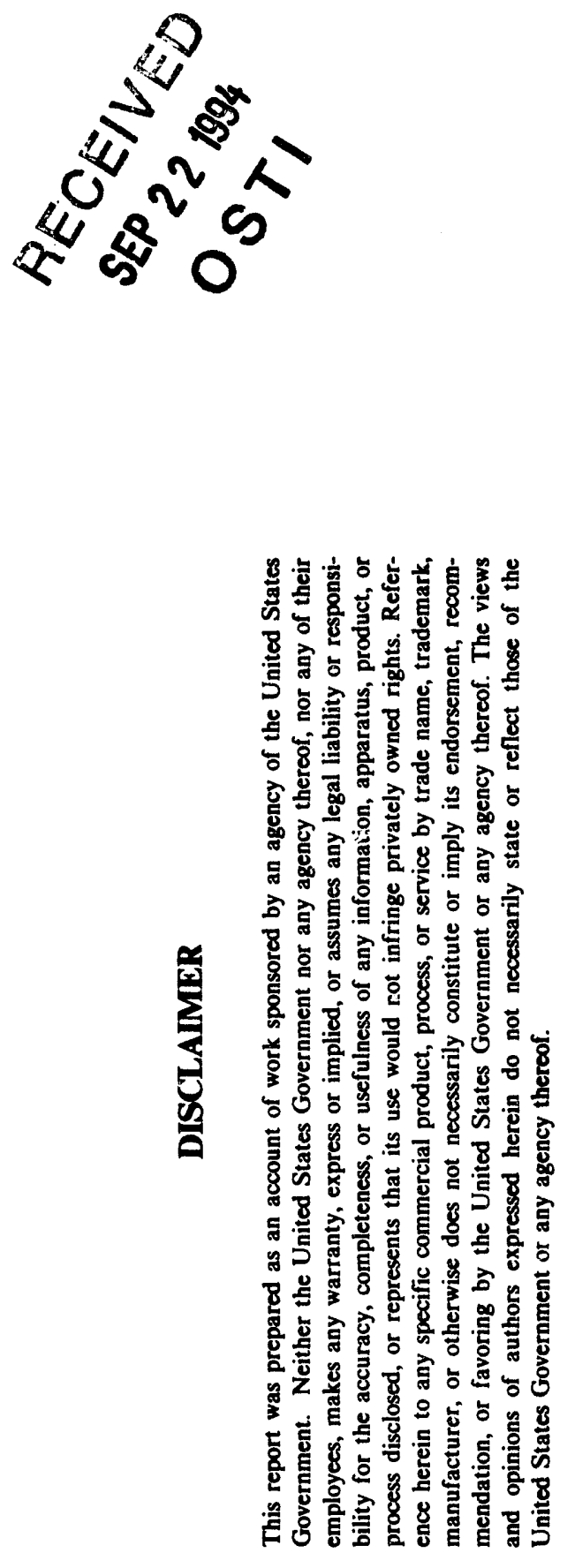

\section{An Investigation of The}

\section{Effects Of History Dependent}

Damage In Time Dependent

Fracture Mechanics; Phases

I, II, and One Half of Phase

III - Variable Load

\section{Conditions}

To

Department of Energy

Office of Basic Energy Sciences

October 15, 1993

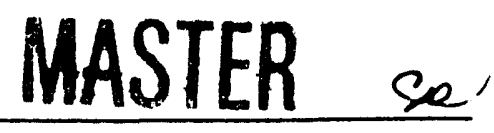




\section{PROGRESS REPORT}

on

AN INVESTIGATION OF THE EFFECTS OF HISTORY DEPENDENT

DAMAGE IN TIME DEPENDENT FRACTURE MECHANICS; PHASES I,II, AND ONE HALF OF PHASE III - VARIABLE LOAD CONDITIONS

to

Department of Energy

Office of Basic Energy Sciences

October 15, 1993

Grant No. DE-FG02-90ER14135

by

F. W. Brust, P. Krishnaswamy, and B. S. Majumdar

BATTELLE

505 King Avenue

Columbus, Ohio 43201-2693 


\title{
PROGRESS REPORT
}

on

\section{AN INVESTIGATION OF THE EFFECTS OF HISTORY DEPENDENT DAMAGE IN TIME DEPENDENT FRACTURE MECHANICS; PHASES I, $\mathrm{I}_{\text {, AND }}$ ONE HALF OF PHASE III - VARIABLE LOAD CONDITIONS}

by

\author{
F. W. Brust, P. Krishnaswamy, and B. S. Majumdar
}

BATTELLE

Columbus, Ohio

Grant No. DE-FG02-90ER14135

\subsection{INTRODUCTION}

The demands for structural systems to perform reliably under severe temperatures and load conditions continue to increase. These demands will continue with the development of advanced power generation methods, for aging nuclear and fossil fueled power plants, and for future aerospace applications. An understanding of the high-temperature creep crack growth process, which is a frequent failure mechanism in these structures, is important. Many investigations which have appeared to date are concerned with creep crack growth which occurs under a constant load and temperature. However, most structural components experience complicated load histories. The history of degradation and damage which accumulates at the crack tip is greatly influenced by these transients. This program aims at gaining an understanding of the history dependent high temperature failure process through a combined experimental and analytical effort. The development of a useful predictive methodology for characterizing this process is being undertaken.

\subsection{PROJECT OVERVIEW}

Objectives. The goal of this research project is to develop a fundamental understanding of the deformation and failure response of cracked bodies which experience history-dependent or cyclic loading at high temperatures. At these temperatures, time-dependent response is important. The 
effects of load and temperature history on time dependent crack growth and fracture were investigated through a combined experimental/analytical approach. In particular, the purpose is to examine and develop the predictive capability of certain analytic techniques through direct comparison to carefully performed experiments. Peripheral objectives include: (i) The development of a computational tool which includes a number of high-temperature constitutive laws, crack-growth features, and the ability to calculate a number of fracture parameters; (ii) The development of an experimental data base in order to develop a detailed understanding of the history-dependent failure process and to verify analysis model; and (iii) To model the experiments developed in (ii) so that a high-temperature history-dependent fracture methodology can be developed and verified.

Planned activities over the next six months include completing analyses of all tests, since all experiments are complete at this point. Planned activities in future years include studying the historydependent creep response in three-dimensional bodies-for instance, for surface-cracked pipes.

Because the modeling of growing surface cracks in three-dimensional bodies is quite difficult, we plan to extend a gridless numerical technique called Smoothed Particle Hydrodynamics (SPH) to enable the history-dependent creep-crack growth response to be modeled effectively. SPH was developed by astrophysicists in the 1970's and has been recently extended and applied with great success at Battelle for ballistic impact problems. In addition, we plan to study history-dependent creep-crack growth response in bodies subjected to different severe conditions to further validate the predictive methodology.

DOE Mission. Many components in power- and energy-generation plants must operate in a severe high-temperature environment. In the future, these demands are expected to increase. Also, current power generation facilities, both nuclear and fossil fueled, are aging now, and methods to predict their extended life are needed. Hence, an understanding of the high-temperature cyclic response of these components, as well as a predictive life methodology, is very important to the DOE goal of providing safe and cheap energy to the USA.

Relation To Other DOE Programs. There are a number of other DOE-funded programs aimed at studying fracture response at room temperature under elastic and elastic-plastic conditions including a strong effort to examine constraint effects in three-dimensional crack growth. In addition, there are several programs which are developing constitutive laws for predicting the high-temperature creep response of steels. To our knowledge, there are no current programs which are studying hightemperature history-dependent creep fracture response. One of the constitutivc laws we are using for 
our studies was developed in a DOE-funded program. In addition, as we study the surface-crack creep problem, we will build on the DOE-funded developments of constraint effects for elastic-plastic fracture and attempt to extend the methods to be applicable for creep fracture.

\subsection{TECHNICAL CONTENT AND APPROACH}

This project was divided into three phases, each phase examined a different aspect of the high-temperature crack growth problem, and each to last (nominally) one year.

Schedule. The schedule of major research activities for this project are summarized for each phase in the following.

During the Phase I effort, the bulk of the computational model was developed, including implementation of constitutive laws, fracture parameters, and other numerical features. In addition, some of the mathematical and physical bases for the integral parameters were investigated. Analyses were also performed for constant load tests and for simulated load-history tests.

During Phase II, the experimental procedure was developed, and a total of nine tests were performed-five on 316 stainless steel and four on a $9 \mathrm{Cr}$-Mo steel. In addition, the analysis code was improved and analyses of some of the tests were performed.

The current Phase III effort consists of performing analyses of all of the tests, trying to develop an understanding of the results, and attempting to develop a predictive fracture methodology for this class of problem. In addition, asymptotic studies of cyclic creep crack-tip fields, as well as studies of cyclic-creep constraint issues, are being addressed.

Technical Issues Currently Being Addressed. Some of the current significant technical issues being addressed are constitutive law effects, experimental anomalies regarding cyclic reload effects, validity of analyses and fracture parameters, and the general philosophy of cyclic-creep fracture. These issues are briefly summarized separately (respectively) in the following paragraphs.

Classical creep constitutive laws (Norton, Strain-Hardening), a law based on the concept of a creep-hardening surface (Murakami-Ohno), and a phenomenological law (based on the Krempl overstress theory and developed by ORNL) are being used to model a cracked body undergoing cyclic creep. The asymptotic crack tip fields appear to strongly depend on which constitutive law is used when load history is accounted for. The significance of this issue is that current engineering approaches, which are based on estimating the strength of asymptotic fields based on classical creep laws, may result in errors when used to predict cyclic creep crack growth using Miner's Rule. In 
addition, energetic approaches being considered here may be more useful since they are not tied to a particular constitutive law.

It has been observed experimentally that, in general, when a crack growing in a creeping solid is unloaded (to zero global load), then reloaded, the displacement rates (as measured at the load line) after reloading are consistently larger than those before unloading. This clearly suggests that the effect of the unload/reload is to damage material in the crack-tip region and is detrimental to the life of structures undergoing such conditions. However, one of our experiments on 316SS did not completely show this trend. Through the analyses we are attempting to understand under what conditions this anomaly occurs. It has important practical significance to understand when cyclic creep has detrimental effects on creep-crack growth and when it does not.

The analyses consist of applying a time history dependent load in an experiment. We may then directly compare predictions of load-line displacements to experimental results. Since constitutive law constants are invariably determined from uniaxial tests at stress levels considerably less than those that occur near a crack tip, it is important to observe how accurate our predictions are. The significance of such a combined experimental/analytical approach is clear; if we can predict the experimental response accurately, then we have confidence that our complete full-field analysis is accurate and evaluations of fracture parameters are adequate.

Perhaps the most important technical issue currently being addressed is whether the effects of load history-dependent creep-crack growth can be predicted accurately. The possibility of using a resistance-curve approach analogous to that used in classical elastic-plastic fracture is being investigated. Here, however, the fracture parameter is an integral parameter (five are currently being considered) rather than the J-integral. With such an approach, crack initiation and reinitiation after reload can be predicted. Note that current app roaches, which consist of relating crack-growth rates to an asymptotic rate parameter, cannot adequaiely address creep-crack initiation or reinitiation after an unload.

Approach. A combined experimental and analytical approach is being taken in this project. The techniques used for both approaches are described separately in the following.

Experiments. Two materials were chosen to study: 316 stainless steel (SS) and $9 \mathrm{Cr}-\mathrm{Mo}$ steel. Both materials will continue to be used in future high-temperature energy-development applications. Material was provided by Oak Ridge National Laboratory (ORNL), and they have carefully characterized the constitutive response of both materials. This permits us to concentrate on fracture tests only. 
A total of nine tests were performed; two on $316 S S$ at $650 \mathrm{C}$, three on $316 S S$ at $593 \mathrm{C}$, and four on $9 \mathrm{Cr}$-Mo at $538 \mathrm{C}$. All specimens are standard compact tension specimens which were machined and fatigue pre-cracked prior to testing. The 9 CR-Mo specimens had approximately 20 percent side grooves machined into them to enforce straight crack growth. Table 1 lists the cest matrix. During the testing phase, one 316 SS specimen at $593 \mathrm{C}$ experienced failure of one of the electric potential (EP) leads which measure crack growth rates, which leads to incomplete crackgrowth data. Two separate EP leads were then used for all other tests. In addition, one variable load $9 \mathrm{Cr}$-Mo test experienced failure in one of the threaded loading fixtures.

The constant load tests of Table 1 were tested in a creep machine. For the variable load tests the experimental technique is automated with the load history programmed on an Instron Servohydraulic machine. This required development of a novel spring-loaded extensometer system. Data acquisition was triggered by load changes. This is desired for comparing test results to analysis results.

Table 1. Tests Performed

\begin{tabular}{|l|l|c|}
\hline MATERIAL & TEMPERATURE & TYPE OF TEST \\
\hline $316 S S$ & 650 Degrees C & 1 Variable Load, 1 Constant Load \\
\hline $316 S S$ & 593 Degrees C & 1 Variable Load, 2 Constant Loads \\
\hline 9 Cr-Mo & 538 Decrees C & 3 Variable Loads, 1 Constant Load \\
\hline
\end{tabular}

Analysis. The analysis approach consisted of first determining which types of creep fracture parameters should be considered for characterizing load history-dependent fracture. This also involved attempting to investigate a mathematical/physical basis for these parameters. Next, constitutive laws capable of characterizing the deformation response under creep-fatigue conditions were identified. The fracture parameters, constitutive laws, crack-growth features, etc. were implemented into a finite element code to enable analyses of the test results described above to be undertaken.

Analyses of experiments were then performed. First, analyses of $1 \mathrm{Cr}-\mathrm{Mo}$ experimental results reported in the literature were performed and simulated load history analyses were performed. Next, analyses of the experiments discussed above were made and are continuing. These analyses for 
the load history-dependent tests are made for the entire history of the test and are quite intensive. For instance, an analysis of one of the $9 \mathrm{Cr}$-Mo tests throughout the entire month-long test, which consisted of more than twenty-eight load/unload sequences, required a Cray computer (which was graciously supplied by DOE). The details of the predicted displacements are carefully compared to the experimental data for both the overall response and for detailed response after a load/reload sequence in an effort to verify the analysis methods. The performance of the fracture parameters is then evaluated by determining which parameters can characterize the response most adequately.

Additional asymptotic analyses under cyclic load conditions were performed using an extremely refined mesh for a stationary crack using both classical and the above-described constitutive laws. This was done because current creep fracture methodology is based on the strength of asymptotic fields using classical (simple) constitutive laws. Hence, we could determine the importance of the chosen constitutive law on the asymptotic fields for cyclic loading.

Problem Importance. Today, in engineering practice, creep fatigue-life predictions are made using Miner's Rule: fatigue and creep crack growth rates are separated and assumed independent. Moreover, the creep portion of the life is based on asymptotic solutions using very simple constitutive laws. Hence, creep-fatigue life predictions are often not very accurate and can lead to safety concerns. Indeed, several high-energy steam piping failures have recently occurred in fossil power plants with serious consequences. Hence, our attempt to develop a unified creep-fatigue life prediction methodology which is more accurate compared to today's methods is important so that advanced power-generation equipment may be designed and used with confidence throughout its life.

\subsection{SUMMARY OF RESULTS}

Recent Accomplishments. Here we present a summary of some of the major, recent accomplishments. Please refer to the papers, which are attached as appendices at the end of this report, for a much more detailed account of all of this work. We first discuss some experimental results, and then provide analysis predictions. In all, a total of nine experiments were performed, all of which are complete to date. Analyses of the experiments have been performed and continue.

Experimental Observations. Table 1 lists the completed tests. The original plan was to perform a total of six tests on one material. However, through cooperation with Dr. R. Swinderman of ORNL, who provided material, it became possible to perform more tests.

Let us first examine some of the general conclusions which can be made regarding history- 
dependent loading in the time-dependent deformation regime. Figure 1 illustrates a load versus time sequence that was applied to one of the $9 \mathrm{Cr}$-Mo compact tension specimens at $538 \mathrm{C}$. An initial load period of 36 hours was made to ensure the development of an initial creep zone in the specimen. The unload hold times and subsequent reload times were continually decreased until about 90 hours, after which four-hour hold periods and one-hour unload periods were maintained until the specimen failed. This assured a truly variable load history.

An enlargement of the displacement versus time history for this experiment between 325 and 365 hours after beginning the test is illustrated in Figure 2. This specimen failed after about $\mathbf{4 0 0}$ hours. Another specimen was loaded to the same load level and was identical in all other ways to the above-described specimen except for a slightly larger initial crack. However, this specimen was held for 320 hours before unload/reload occurred, and only one cycle was applied. Figure 3 illustrates the displacement versus time history for this test. Note that this test failed at more than 600 hours.

Several important general conclusions can be drawn from these results:

- During the unload-hold period, load-point displacement recovery occurs. This is due to the compressive stresses which develop at the crack tip during unload. The compressive stress zone size can be quite large, as was verified through computational studies, even though the global load is never less than zero.

- After reload, the displacement rates increase compared to the rates during the previous loading period. This is clearly seen in Figures 2 and 3 . Note also that the displacement just after reloading is always smaller than the corresponding value just before unloading.

- Load-history effects significantly decrease life compared to the nearly constant load (only one unload) test, i.e., in this case the constant load test lasted nearly 1.5 times longer.

Observations from Analysis. Here we briefly show results of an asymptotic study before showing results from an analysis of an experiment. Consider a stationary crack subjected to the following load sequence: (i) Load with 24-hour hold period, (ii) unload (to zero load) and hold for one hour, (iii) reload and hold for 24 hours, (iv) etc. This means that the end of the load-hold 


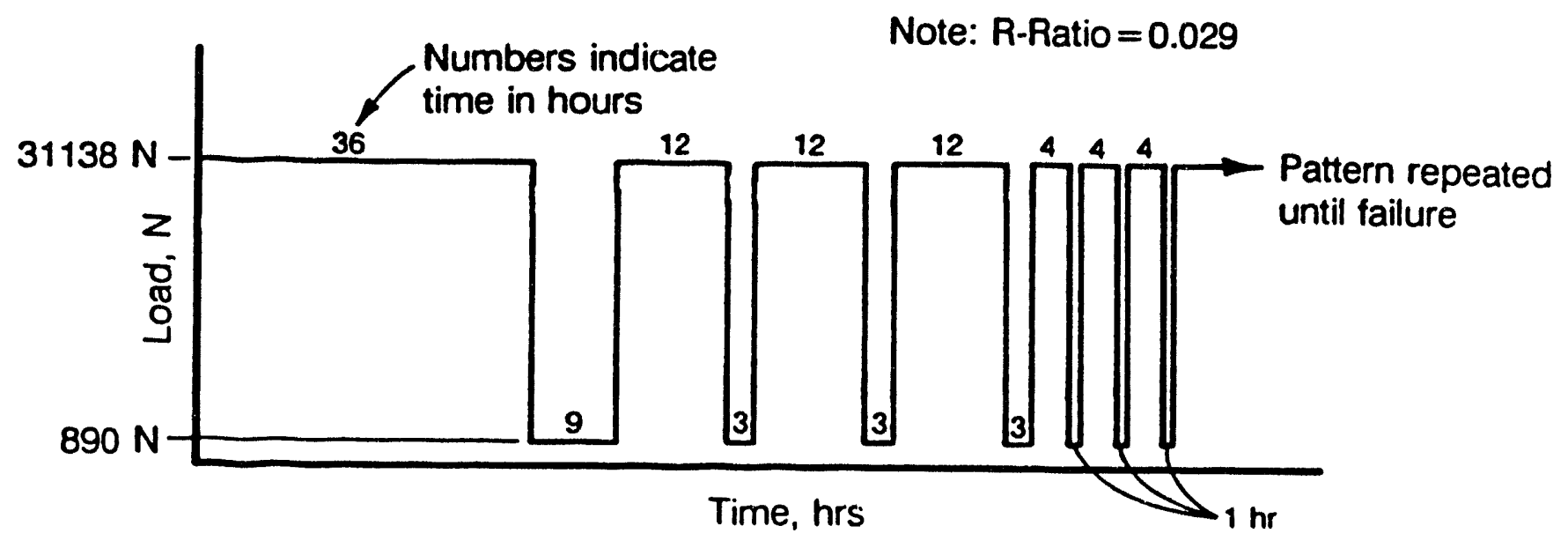

Figure 1. Load time sequence applied to the second $9 \mathrm{Cr}-\mathrm{Mo}$ test.

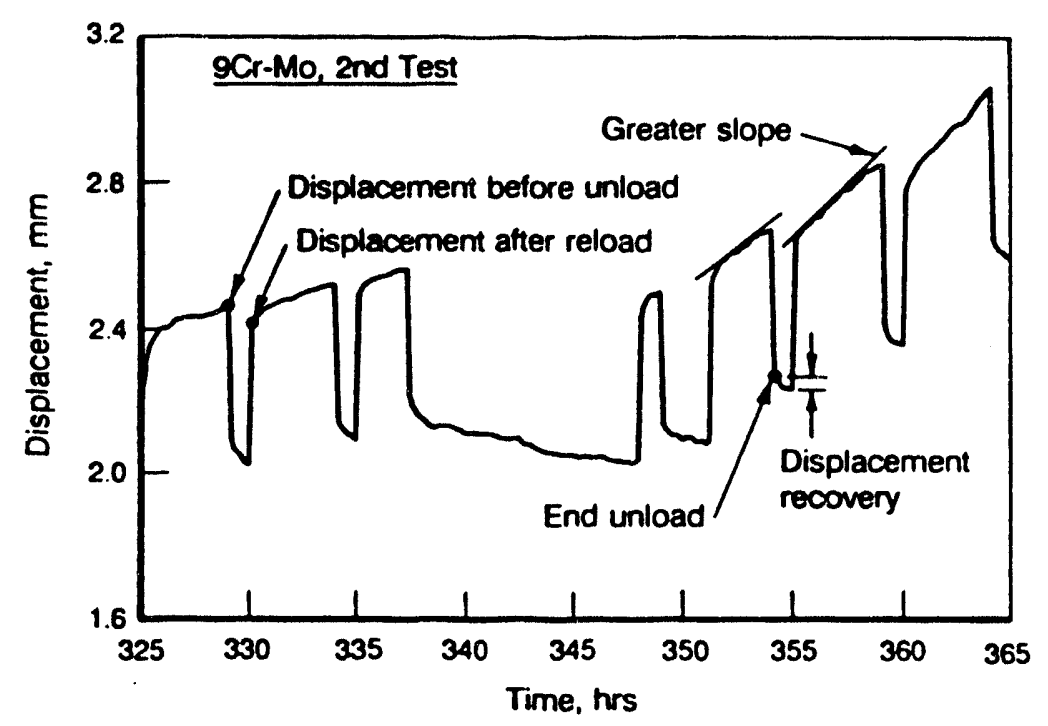

Figure 2. Displacement time history for second $9 \mathrm{Cr}$-Mo test.

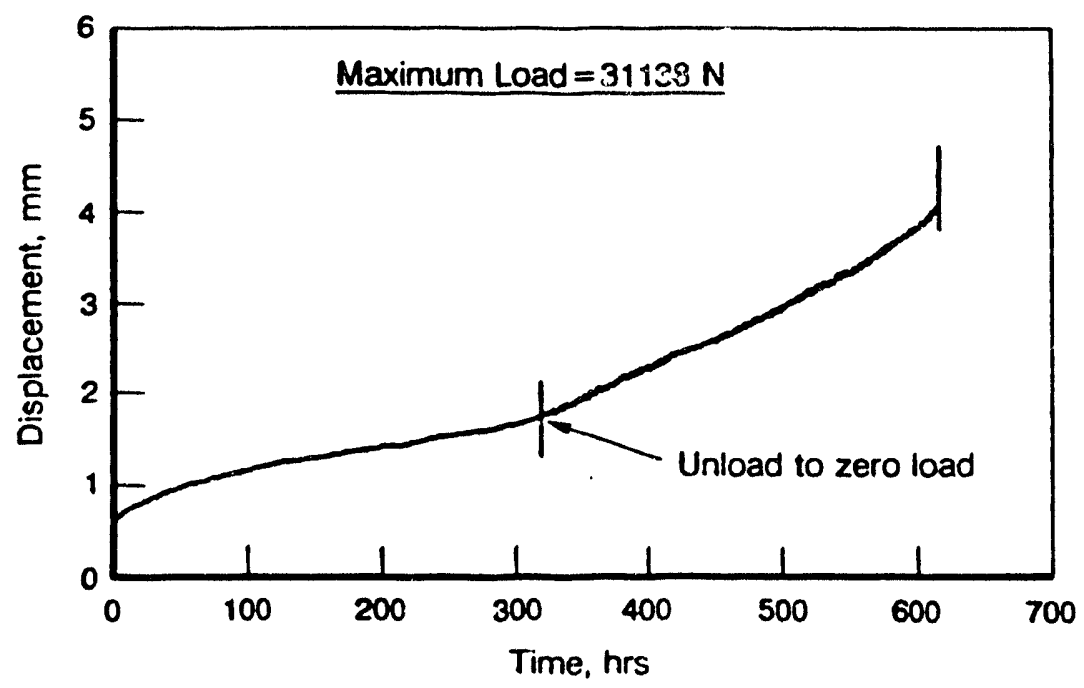

Figure 3. Displacement time history for third $9 \mathrm{Cr}$-Mo test. 
periods were 24, 49,74, and 99 hours. An extremely refined symmetric finite element mesh was developed with 10 rings of six-noded isoparametric triangular elements surrounding the crack tip and eight-noded elements elsewhere with the crack-tip element size equal to .0005 times the uncracked ligament. This refinement is about 2.5 times more refined compared with the classical HRR field studies of Shih and German. A classical strain-hardening (S-H) and the Murakami-Ohno (M-O) cyclic creep law were used to model the problem. Creep properties for $9 \mathrm{Cr}$-Mo steel were used. Figure 4 illustrates the theta component (i.e., perpendicular to the crack) of creep strain as a function of the distance, $R$, ahead of, and parallel to, the crack. Note that the creep strain as calculated using the M-O law continuously drifts away from the strains evaluated using a classical law. This is because the creep strain rates after a change in stress direction which occurs near the crack during global load changes become very large. This is observed both experimentally and predicted using MO. The S-H law cannot capture this effect. The importance of this is that the true deformation response of the cracked body must be accounted for in order to adequately predict the damage accumulation near the crack. Examination of stresses also reveals that the strength of the asymptotic field also changes from cycle to cycle. We thus conclude that current engineering methods, which are based on correlating creep-crack growth rates to the strength of an asymptotic field assuming a classical creep law (and constant load conditions), may not be universally valid for variable load conditions.

Finally, the analysis results of one of the $9 \mathrm{Cr}$-Mo tests (i.e., first test) are presented. This specimen had a load sequence consisting of (i) load and hold for 24 hours, (ii) unload and hold for 5 minutes, (iii) reload and hold for 24 hours, etc., (i.e., different from Figure 1 and 3). The maximum load was $23.353 \mathrm{KN}$, and the minimum load was zero. The finite element model was forced to follow the load-time and crack-growth history. Load-line displacements were predicted as well as a number of potential fracture parameters. The fracture parameters considered here are integral parameters, which have an energetic physical interpretation. The $T^{*}, J_{W}$ (Watanabe), $J_{M}$ (McClintock), $\hat{\mathrm{J}}$ (Aoki, et al.). and $\mathrm{J}_{\mathrm{B}}$ (Blackburn) integrals were evaluated throughout the history (please see references for detailed discussions of these parameters). The crack initiated at about 192 hours and failure occurred after 700 hours in the test. Note that the entire load history was modeled.

Figure 5 shows a comparison of the maximum displacements (at the end of the load-hold period) and minimum displacements (at the end of the unload-hold periods). It is seen that the predicted displacements compare quite well with the experimental results, which suggests that the m is adequate. The predicted displacements begin to accelerate upward at about 600 hours while 


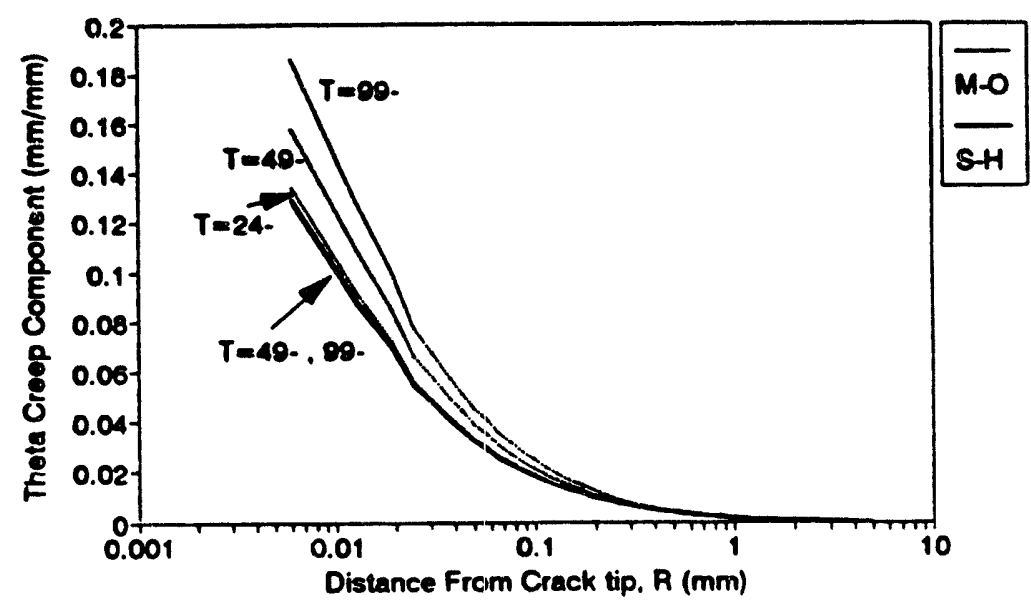

Figure 4. Asymptotic creep strains.

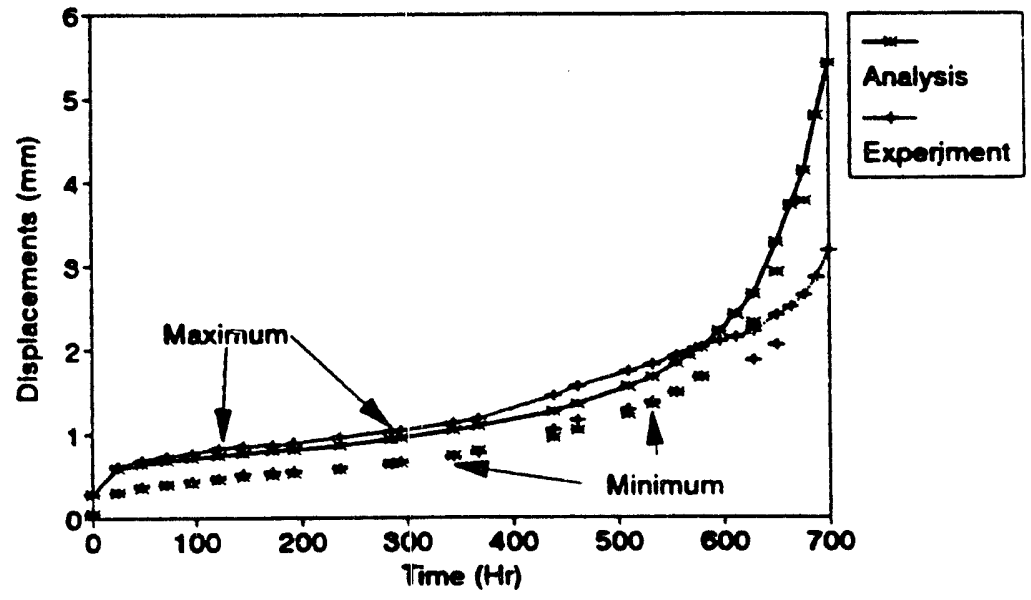

Figure 5. Displacement comparisons for first $9 \mathrm{Cr}-\mathrm{Mo}$ test. 
the experimental results begin to increase at about 650 hours, i.e., the analysis predictions are a little conservative here. The displacement trends of displacement recovery after unload, and displacement rates increasing after reload (of the type illustrated in Figure 2) were also predicted reasonably well compared to the data.

Figure 6 compares all of the integral parameters as a function of time. As indicated in Figure 6, crack growth begins at about 192 hours, after the eighth unloading. Note that, before crack growth, all of the integrals experience a step jump after a load cycle indicating that variable loads increase creep damage conditions as measured by these parameters. Note that the $T^{*}$ and $J_{w}$ integrals attain a nearly constant value during the crack-growth phase (observe the horizontal lines in Figure 6). This result suggests that a constant value of $T^{*}$ or $J_{W}$ may characterize crack growth under creep fatigue conditions. Moreover, crack initiation can be predicted. Aî about 628 hours the integral parameters become unstable, suggesting that crack instability is predicted. While the results of one test are not conclusive, it suggests that these parameters may have the capability to predict this type of behavior. The results of the other tests are currently being analyzed and are not quite available as yet.

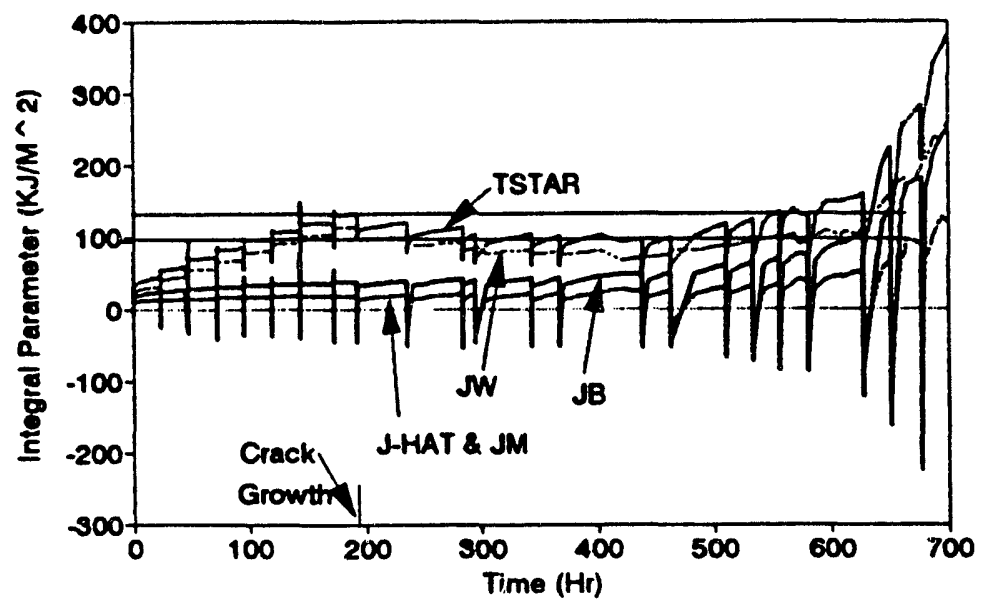

Figure 6. Behavior of integral parameters for first $9 \mathrm{Cr}$-Mo test.

\subsection{PRESENTATIONS AND PUBLICATIONS}

A number of symposium presentations based on the work performed during this program were made, along with a number of journal publications. The following list describes those efforts which are in print. Publications are listed as follows (in chronological order of submission). 
1. Krishnaswamy, P., Brust, F. W., and Ghadiali, N. D., "A Finite Element Algorithm To Study Creep Crack Growth Based On The Creep Hardening Surface," submitted to Int. Journal For Num. Meth. In Enginesring, December 1991. Revised version submitted August 1993.

2. Brust, F. W., Krishnaswamy, P., and Majumdar, B. S., "Consideration Of History Dependent Damage In Creep Crack Growth," proceedings of the Tenth Symposium on Energy Engineering Sciences, Synergism of Analysis, Modeling, and Experiment, May 11-13, 1992, Argonne, Illinois.

3. Krishnaswamy, P., Brust, F. W., and Ghadiali, N. D., "Finite Element Analysis Of History Dependent Damage In Time Dependent Fracture Mechanics," in Fatigue. Fracture, and Risk, 1991 edition, by Bamford, W. H., et al., ASME-PVP Volume 241, 1992. Also, this paper was invited to be published in the ASME Journal Of Pressure Vessel Technology and will appear in 1994.

4. Brust, F. W., Krishnaswamy, P., "A Computational Study Of The Time Dependent Crack Growth Process," in ASME Applied Mechanics Division Volume (AD-Vol. 27), edited by A. Nagar, et al., November, 1992.

5. Brust, F. W. and Majumdar, B. S., "Load History Effects On Creep Crack Growth," submitted to Engineering Fracture Mechanics, December, 1992. Under review.

6. Brust, F. W., Majumdar, B. S., "Studies Of Creep Crack Growth Under History-Dependent Loading" presented at ICF-8, Kiev, Ukraine, June 1993. To appear in Conference Proceedings. Also, invited by editors to be published in the International Journal of Material Science. To appear 1994.

7. Brust, F. W., Krishnaswamy, P., and Majumdar, B. S., "Further Studies Of History-Dependent Loading In The Creep-Crack Growth Regime," in Fracture Mechanics - Applications and New Materials, ed. A. Mehta, PVP-Vol. 260, July, 1993.

8. Krishnaswamy, P., Brust, F. W., "Finite Element Modeling Of Creep Crack Growth In 316 Stainless and $9 \mathrm{Cr}-1 \mathrm{Mo}$ Steels, " proceedings of 11 th International Invitational Symposium On The Unification of Analytical, Computational Solution Methods, Boston, Massachusetts, August, 1993.

9. Brust, F. W., "Investigations Of High Temperature Damage And Crack Growth Under Variable Load Histories," submitted to the International Journal Of Solids And Structures, September, 1993.

10. Brust, F. W., "Asymptotic Investigations Of Cyclic Creep Fracture Response", under preparation (work is complete), to be submitted to Theoretical and Applied Fracture Mechanics, 1993.

11. Brust, F. W., and Majumdar, B. S., "Analytical and Experimental Studies of History Dependent Creep Fracture", under preparation, to be submitted to the International Journal of Fracture, 1994. 
13

Symposia presentations already planned in 1994 are to be made at the Twelfth U.S. National Congress of Applied Mechanics, June, 1994, and the 26 th National Symposium on Fracture Mechanics, June, 1994. These two symposia also require proceedings papers to be written. In addition, we will probably also present work at the 1994 ASME Winter annual meeting, and will write one more journal paper after the work is complete, and send to the International Journal of Fatigue.

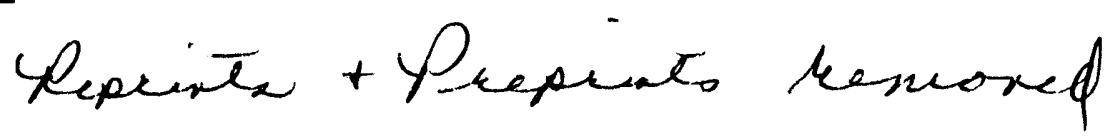



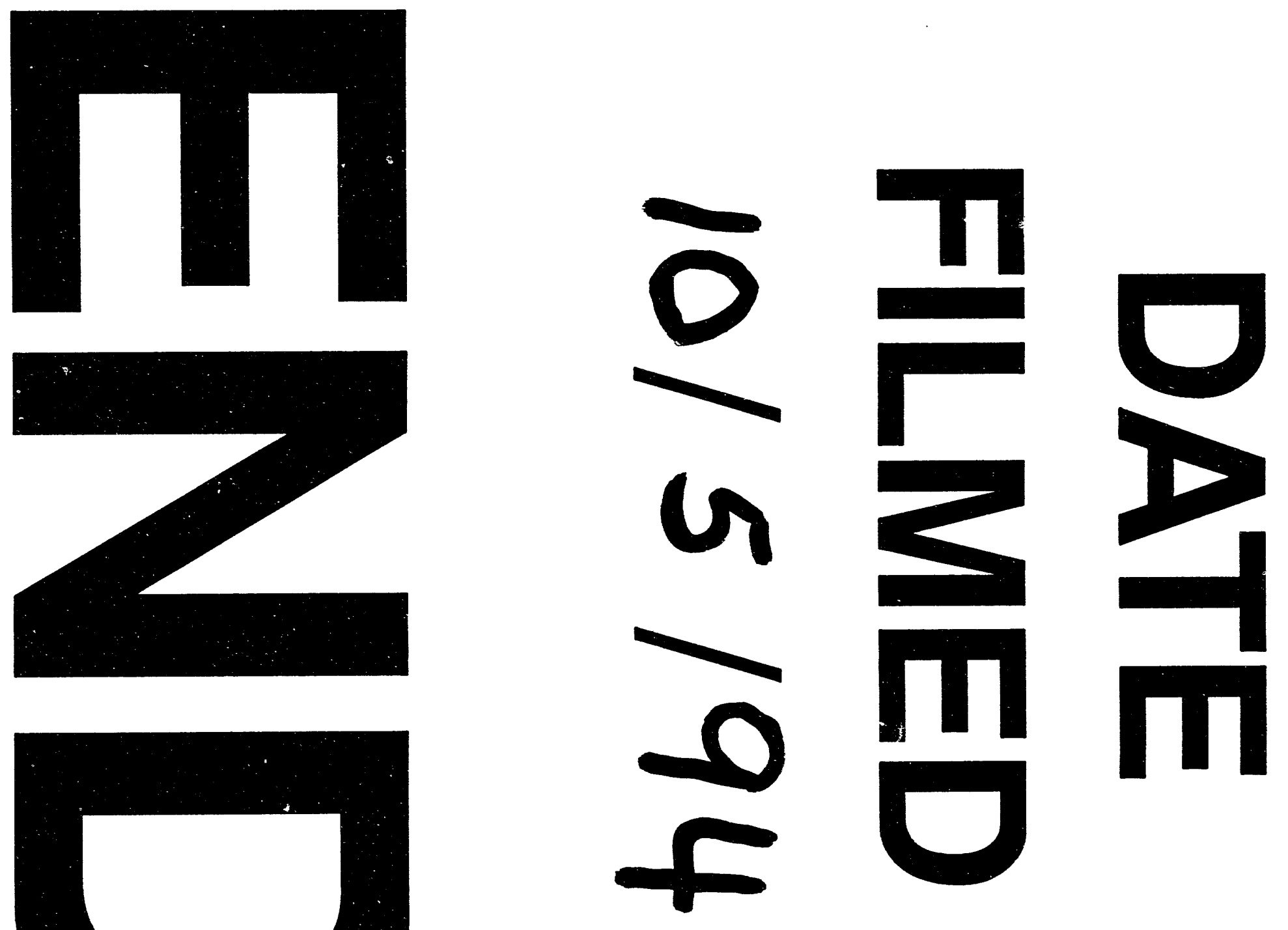
